\title{
DO IMPRESSO À PELÍCULA: TRADUÇÃO INTERSEMIÓTICA E CONFIGURAÇÕES DA (HOMO) AFETIVIDADE FEMININA EM A COR PÚRPURA, DE ALICE WALKER
}

\author{
Edimar Pereira da Silva ${ }^{1}$ \\ Ariovaldo Lopes Pereira ${ }^{2}$ \\ Débora Cristina Santos e Silva ${ }^{3}$
}

\section{Introdução}

Estudos dedicados à relação entre literatura e cinema são uma eficaz ferramenta para analisar as articulações entre distintos sistemas sígnicos, tais como o verbal e o sonoro-visual. Em sua condição de tradução intersemiótica, a adaptação fílmica é um privilegiado objeto para investigações científicas no âmbito da literatura. Nessa perspectiva, o objetivo deste artigo é promover uma reflexão acerca das configurações da (homo)afetividade feminina, para além da sexualidade em si, a partir do intercâmbio entre o diálogo intersemiótico entre as versões literária e fílmica da obra $A$ Cor Púrpura, escrita por Alice Walker em 1982 e transposta para o cinema por Steven Spielberg em 1985.

Utilizaremos como base desta reflexão, o método de análise comparativa. Ambos os textos pertencem a sistemas semióticos distintos, razão pela qual faz-se necessário a retomada de diferentes conceitos de tradução, que atuem em contextos e circunstâncias de adaptação cinematográfica de uma obra literária - também chamada de "tradução intersemiótica". Esses conceitos e certas reflexões sobre a profícua relação entre literatura e cinema, bem como a especificidade da linguagem de cada uma destas artes, serão pautados pelas representações entre os signos e seus objetos. Nesse sentido, Santaellla (2002), define as formas de representação do signo em relação ao seu objeto, no sentido icônico, que se dá pelas marcas causadas pelo objeto. Para a autora, o signo

\footnotetext{
${ }^{1}$ Mestrando do Programa de Pós-Graduação em Educação, Linguagem e Tecnologias da Universidade Estadual de Goiás (MIELT-UEG). silva.edimarpereira@gmail.com

${ }^{2}$ Professor do curso de Mestrado Interdisciplinar em Educação, Linguagem e Tecnologias da Universidade Estadual de Goiás/Anápolis. Mestre em Linguística Aplicada pela Universidade de Brasília. Doutor em Linguística Aplicada pela UNICAMP. arylopes_br@yahoo.com

${ }_{3}^{3}$ Professora do Mestrado Interdisciplinar em Educação, Linguagem e Tecnologias da Universidade Estadual de Goiás. Mestre em Letras e Linguística pela Universidade Federal de Goiás. Doutora em Teoria Literária UNESP/ 2002, com Estágio Pós-doutoral em Literatura e Hipermédia pela Universidade Fernando Pessoa. desants@uol.com.br
} 
estabelece uma relação de fato (concreta) com o objeto, em virtude de ser afetado por ele. O signo aponta para o seu objeto por ser uma parte deste. As possibilidades interpretativas são fechadas. Por ser uma relação dual, na qual signo e objeto estão conectados, o potencial interpretativo dos índices se reduz à ligação existencial de um signo indicando seu objeto (SANTAELLA, 2002, p. 6).

Acreditamos que o trabalho sobre tradução se faz pertinente, pois nos possibilita identificar as influências que atravessam o meio cinematográfico, assim como as suas características artísticas específicas. Em outras palavras, falar de processos de adaptação entre meios é basicamente falar das especificidades de diferentes linguagens.

Com base nessas reflexões, buscamos compreender: a) Quais as (inter)relações possíveis entre Literatura e Cinema? Como se dá a interlocução no romance epistolar no processo das Intersemioses textuais entre o impresso e a película? E quais as traduções da sexualidade e expressões (homo)afetivas, em $A$ cor púrpura, são evidenciadas no processo de tradução intersemiótica?

Com efeito, o foco deste estudo, direciona-nos a compreensão de que a relação entre as obras não se dá apenas pelo direcionamento à fidelidade ao texto fonte, como uma repetição de uma obra anterior, mas evidencia o que vem a ser uma construção interpretativa, uma vez que "o texto literário é um signo com múltiplas interpretações possíveis [...] e pode motivar inúmeros interpretantes” (ESPÍNDOLA, 2008, p. 36). Em vista disso, Espíndola (2008), afirma ainda que

a atualização do signo literário num filme pode ser visto como a materialização da leitura em cena, o que proporciona a percepção da potência sígnica como ato interpretativo, que pode acrescentar elementos ao texto de referência, que não exige que o leitor conheça o original, tornando-se uma obra de arte independente. (ESPÍNDOLA, 2008, p. 38).

No contexto da obra, tomada pelos encantos artísticos de Doci Avery, cantora que se apresenta na região, por quem Celie se aproxima e de maneira ainda tímida e amistosa vai se deixando levar pelos encantos de conhecer, aceitar e dominar seu próprio corpo, compreendendo seus desejos, anseios e a paixão por alguém do mesmo sexo. Neste âmbito, busca-se analisar neste texto, como se da à representação do (homo)erotismo feminino entre às artes fílmica e literária.

Traçando um panorama geral de A cor púrpura (1982), de Alice Walker temos: duas irmãs negras, órfãs e habitantes de uma região rural do Sul dos Estados Unidos deparam-se com a violência social e sexual de uma sociedade marcada pela miséria, pelo racismo e pelo sexismo. Enquanto Celie resigna-se diante da opressão estabelecida pelo meio social e pelo elemento masculino, tornando-se esposa de um marido violento e 
trabalhadora rural, Nettie rebela-se contra a mesma opressão e migra para a África na condição de missionária e professora.

Implicações sobre a dinâmica sobre os estudos sobre a identidade vão ao encontro das reflexões de Hall (2006), e sobre a origem dos estudos culturais e aos estudos advindos do marxismo ${ }^{4}$, que deixavam de responder às demandas de grupos sociais de sua época, inicialmente operários, aos quais se somaram os imigrantes, negros, feministas e outros.

Portanto, a reflexão acerca das semioses em que se figura o (homo)erotismo feminino para além do ato sexual, aponta a resultados que imprimem em sua composição, fator articulador da dinâmica de identidade, social e cultural brasileira na pósmodernidade.

\section{Inter(artes): da literatura ao cinema}

Embora pertencendo a campos semióticos distintos - um verbal e outro sonoro visual -, literatura e cinema possuem a estrutura narrativa como elemento comum. A narrativa do cinema se assemelha ao romance, pois sua existência envereda-se pela narração, no encadeamento de ideias, no entrelaçamento de temas. Essa narração, no entanto, para se concretizar em linguagem cinematográfica passa por procedimentos, muitos deles próprios da arte cinematográfica. Enquanto a narrativa literária utiliza-se de diferentes tipos de narrador para contar suas histórias (narrador-personagem, narradorobservador, narrador-onisciente...), no cinema, essa função é exercida pela câmera: focaliza, recorta, aproxima, expõe e descreve através do close-up, do setting, ou da panorâmica.

Diante do contexto aqui explicitado, não é difícil perceber a necessidade que sentimos de buscar alternativas de análise da transposição de um romance para a linguagem fílmica; análises que podem levar o espectador/leitor até a constatar, por exemplo, que o reconhecimento de um texto como literário não é determinado por suas características formais, nem pela vontade do falante/leitor autônomo, mas provém de uma decisão coletiva acerca do que conta como literatura, uma vez que o trabalho a partir da

\footnotetext{
${ }^{4}$ Um conjunto de doutrinas diversas (e até antagônicas entre si) que tinham em comum, entretanto, duas características básicas: todas entendiam que a base determinante do comportamento humano residia na esfera moral/ideológica e que o desenvolvimento das civilizações ocidentais estava a permitir uma nova era onde iria imperar a harmonia social. Ver: (MARX, 1984, p. 46-58)

Revista Livre de Cinema

p. $67-78$

v.2, n. 3, set/dez, 2015
} 
transposição da análise do texto literário nos permite uma visão geral das peculiaridades e elementos que atribuem ao texto novas modulações, por meio da arte cinematográfica.

$\mathrm{Na}$ obra, ao se referir às passagens em que o (homo)erotismo feminino é evidenciado, Celie, personagem principal da narrativa, vivia reprimida e recatada ao referir sobre seus sentimentos por Doci Avery, artista amiga, a qual fazia apresentações musicais por temporadas na região, utiliza-se de linguagem abrupta e direta

Eles dois fizeram três nenê junto, mas ele fica com vergonha de dar banho nela. Quem sabe ele pensa que vai começar a pensar em coisa que num deve. Mas e eu? A primeira vez queu vi inteiro o longo corpo negro da Doci Avery cum os bico dos peito que nem ameixa preta, parecendo a boca dela, eu pensei queu tinha virado homem. (WALKER, 1982, p. 53)

Ainda com relação à linguagem empregada no romance, Spielberg (1985), foi mais ambíguo e utilizou mais simbolismo em lugar de ser específico ao se tratar do homoerotismo. Na figura 1, nota-se que: a iluminação natural entrando pela janela evidencia ao centro as duas personagens, luz que nivela tons de pele, tornando-as iguais no contexto; sobre a cor do set, geralmente verde, caracteriza estágio de "amadurecimento" dos desejos, em consonância a pureza de que se contrapõe ao vermelho, símbolo óbvio da manifestação dos sentimentos sexuais e eróticos das personagens em cena.

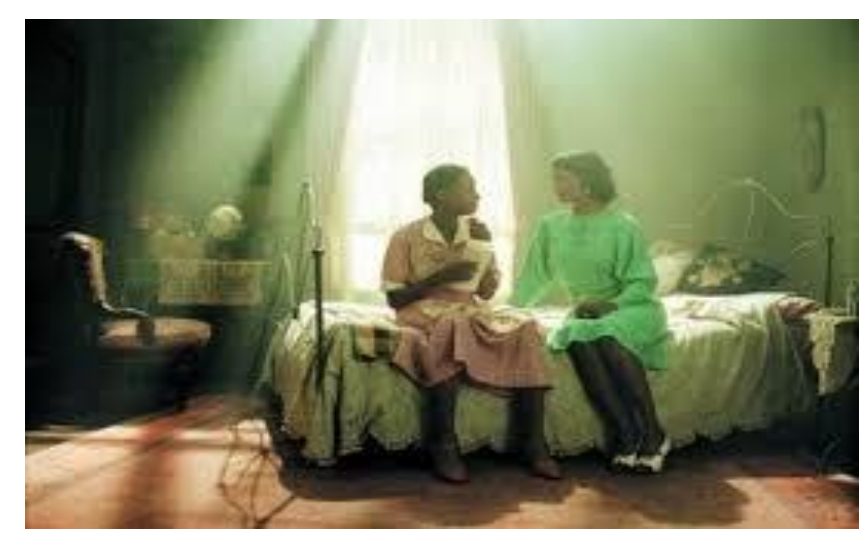

Figura 1: The color purple (1985) 57min 24s

Com sua linguagem híbrida, o Cinema transforma o discurso - no caso, a obra literária - em imagens, som, movimento e luzes. Jakobson (1969) introduziu o conceito de "tradução intersemiótica" para designar a transmutação de uma mensagem de um meio para o outro. Amplia este conceito o produto desta transmutação ser uma obra outra, desvinculada do texto de origem, mas sem perdê-la de vista, em que, ganha-se autonomia e novos sentidos, ou seja, novas semioses. 
Cabe ressaltar que, as artes aqui arroladas, não se excluem, não se repelem, mas, estabelecem um diálogo, se auto-referenciam, se complementam. Já que literatura e cinema se aproximam naturalmente no processo de fruição, ao contrapor dialogicamente duas linguagens artísticas, proporcionam o aprimoramento da sensibilidade estética e ampliam consideravelmente as dimensões e leitura. Para Allegro (2004, p. 34), "Cinema e Literatura, andam juntas comparando obras, cotejando textos de diferentes origens e épocas e aprendendo (e apreendendo) cultura, o comparatista está constantemente emergindo em alteridade cultural".

Portanto, acerca do que fora apontado, viu-se a importância de se refletir sobre as características das produções artísticas culturais - Literatura e Cinema -, assim como se desenvolveram os elementos que (re)significaram a temática da sexualidade da obra escrita para as telas.

\title{
Intersemioses textuais: configurações de interlocução no romance epistolar
}

A reflexão sobre o romance epistolar pode nos levar a compreender modos de constituição histórica do público, ou melhor, dizendo, de um público para o romance. Em A cor púrpura (1982), de Alice Walker, é notório que a linguagem utilizada pelas irmãs Celie e Nettie, ao escreverem cartas, explicita o nível de escolaridade delas: enquanto Nettie (alfabetizada) utiliza o inglês padrão, Celie (semi-alfabetizada) é usuária de uma variedade rural do inglês negro norte-americano, ou seja, a linguagem coloquial. No caso de Nettie, o marco desta correlação seria o fato de ela ter sido alfabetizada, missionária na África (e, portanto, livre da opressão) e usuária da variedade prestigiada do inglês. Bazin (1991), alerta ao cuidado de se valorizar os níveis de linguagem da obra original no processo de transposição às telas:

\begin{abstract}
a diferença de nível e o prestígio artístico da obra original servem meramente de caução ao filme, de reservatório de ideias e de garantia de qualidade [...], ou os cineastas se esforçam honestamente pela equivalência integral, tentando ao menos não mais inspirar-se no livro, mas traduzi-lo para a tela [...] Não apedrejemos os fabricantes de imagens que "adaptam" simplificando. A traição deles, como dissemos, é relativa e a literatura nada perde com isso. (BAZIN, 1991, p. 93-94)
\end{abstract}

Na obra, a repressão e dominação masculina se tornam cada vez mais intragável, Celie se vê em uma redoma, ao aceitar o relacionamento sexual e desprezo pessoal por parte do marido.

Ele olha pra mim. Parece que ele tá olhando pro chão. E ela precisa de alguma coisa? , os olho dele falava. Ela foi cumigo na loja. Eu imagino qual será a cor que 
a Doci Avery usa. Ela parece uma rainha pra mim, então eu digo pra Kate, Alguma coisa púrpura, quem sabe cum um pouco de vermelho também, Mas a gente procura e procura e num acha nada púrpura. Vermelho-vivo tinha mas ela diz, Não, ele num vai querer pagar pelo vermelho. Fica alegre dimais. A gente tem que escolher um marrom, beje ou azul-marinho. Eu digo azul. (WALKER, 1982, p. 28)

Diante deste conflituoso cenário, podemos acreditar que, a escolha do romance epistolar seria justificada pelo contexto de solidão em que se encontrava Celie. Ao perceber sem interlocutor, ou seja, a quem direcionar as cartas, uma vez que o contato entre Celie e Nettie - na África -, havia sido impossibilitado por Albert, que escondia as correspondências e repudiava o fato de Celie saber escrever. Neste ínterim, Celie destina suas cartas a Deus, imerge daí, o diálogo introspectivo e auto-reflexivo, possibilitando assim, tanto na compreensão da dura realidade quanto na fuga da existência rude. "É pior que isso, eu penso. Se eu tivesse interrada, num tinha que trabalhar. Mas eu só digo, Num importa, enquanto eu escrever a D-e-u-s, eu tenho alguma coisa." (WALKER, 1982, p. 26)

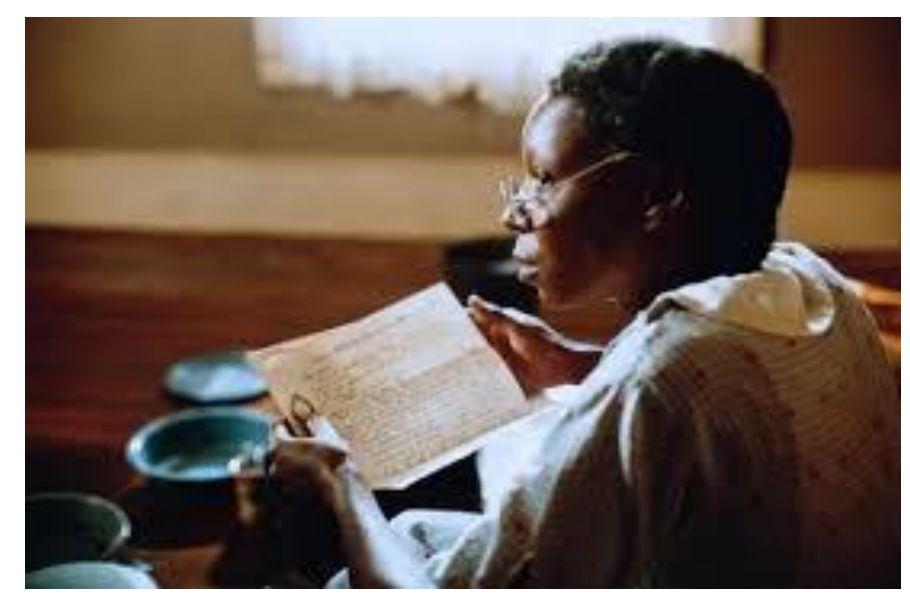

Figura 2: The color purple (1985) 93 min 6s

"Surgimento, multiplicação e sucesso do romance epistolar na Europa do século XVIII, sugerem uma homologia entre, de um lado, práticas sociais de linguagem e de escrita; de outro a mimese de tais práticas na literatura." (LAJOLO, 1993, p. 62). Corroborando com Lajolo (1993), podemos afirmar que, na obra, há um desvio da grande característica do romance epistolar no que reside de sua natureza essencialmente dialógica, ao passo que temos Deus como interlocutor, por vezes, figura do alterego ${ }^{5}$ de Celie, ao apropriar-se da escritura como fuga das mazelas do cotidiano escravista.

Querido Deus, O Harpo pergunta pro pai pur que ele bate em mim. Sinhô diz, Purque ela é minha mulher. Depois, ela é teimosa. Todas as mulher são boa pra...

\footnotetext{
${ }^{5}$ É um termo criado por Freud para conceituar coisas que estão no Ego de uma determinada pessoa, as quais podem ser transferidas para outra, que passa a funcionar como se fosse uma duplicata da primeira pessoa. Ver: (FREUD, 1976, p. 54-57) 
ele num termina. Ele só infia a cara no jornal como ele faz sempre. Me faz lembrar o pai. O Harpo me pergunta, Pur que que você é teimosa? Ele num pergunta, Pur que que você é mulher dele? Ninguém pergunta isso. Eu digo, Eu nasci assim, acho. Ele bate em mim como bate nas criança. Só que nas criança ele nunca bate muito forte. (WALKER, 1982, p. 30)

Mesmo escrevendo cartas destinadas a Deus, Celie, por vários momentos, apresenta-se solitária em sentido dialético textual: "Querido Deus, Eu me sinto meio tonta. Meu pai foi linchado. Minha mãe era louca. Todos os meus meio irmão e irmã num é meus parente. Meu filho num é minha irmã nem meu irmão. O pai num é o pai. Você deve está dormindo." (WALKER, 1982, p. 161). Por vezes, cria que aquele Deus não era o dela ou para ela.

Foi Deus que escreveu a Bíblia, os branco num tem nada a ver cum isso. Então purque ele é igualzinho a eles, heim?. Purque a Bíblia é igualzinha a tudo que eles faz, só tem eles fazendo isso e aquilo, e tudo que tem dos negro é os negro sendo amaldiçoado? Eu nunca pensei nisso. A Nettie diz que em algum lugar na Bíblia ela diz que o cabelo de Jesus era que nem a lã do cordeiro, eu digo. (WALKER, 1982, p. 176)

A verossimilhança no gênero exige ainda que a narrativa epistolar se desenvolva em primeira pessoa. No caso deste romance, o cuidado na construção do eu ultrapassa o nível pronominal. Nota-se na figura 2: A espacialização diferenciada para a escrita, geralmente, Celie escrevia em locais fechados, por vezes, escondida de Albert; a linguagem sempre impregnada de termos regionalistas e coloquiais; a superposição de vozes apontando para a transculturação da personagem, ao descrever hábitos, linguagem e os costumes de Doci Avery, salientava a pronúncia acentuada das palavras, o estilo de leitura aligeirada e, principalmente, o vestuário exótico, características que evidenciam as diferenças entre as classes sociais. Para Bourdieu (1998),

a classe social não se define por uma propriedade (ainda que se trate da mais
determinante como o volume e a estrutura do capital) nem por uma soma de
propriedades (propriedade de sexo, de idade, de origem social ou étnica-
proporção de brancos e negros, autóctones e emigrados, etc. - de ingressos, de
nível de instrução, etc.) nem muito menos por uma cadeia de propriedades
ordenadas a partir de uma propriedade fundamental (a posição nas relações de
produção) em uma relação de causa e efeito, de condicionante a condicionado,
senão pela estrutura das relações entre todas as propriedades pertinentes, que
conferem seu próprio valor a cada uma delas e aos efeitos que exerce sobre as
práticas. (BOURDIEU, 1998, p. 104)

Contudo, a partir de elementos subjetivos que integram a identidade da protagonista, enfatiza-se a exploração do gênero romance epistolar - pois a história é desenvolvida principalmente através de cartas, ainda que, sem interlocutor presente, tem por finalidade o relato do cotidiano, lembrando por vezes, outro gênero narrativo: o diário. $\mathrm{Na}$ análise da obra e do gênero, ao dispormos Deus como único interlocutor das 
epístolas, novas configurações surgem e são constituídas para construção da identidade da personagem protagonista.

\section{A Cor Púrpura: traduções da sexualidade e expressões (homo)afetivas}

Pode-se afirmar, em síntese, que a reflexão pós-moderna sobre tradução, diferentemente do pensamento tradicional - transposição do meio-, pressupõe a prática tradutória como trabalho de interpretação, o qual é realizado por um sujeito situado histórica e ideologicamente, considerando tanto linguagem, como ideologia. O tradutor, ao produzir significados, ao interpretar o texto a ser traduzido, é orientado pelas condições de produção nas quais está inserido. Tal conceito amplia, assim, nossas discussões para outras áreas de conhecimento, ou seja, sobre as interações possíveis entre os fenômenos culturais.

Celie percebe-se admirada pela artista Doci Avery, personagem caracterizada pela espontaneidade e por ser aparentemente livre das mazelas da dominação masculina. Seu desejo vai sendo alimentado e aos poucos, Celie se permite inclinar-se (homo)afetivamente por Doci Avery. Nesse sentido, nossa atenção foi voltada à observação deste aspecto na obra, com o intuito de averiguar como cada meio semiótico - Cinema e Literatura - trabalhou a construção dessas significações da sexualidade. Para Foucault (2006),

A sexualidade, como dispositivo, opera por meio de um conjunto heterogêneo de discursos e práticas sociais, daí sua compreensão exigir procedimentos que articulem elementos tão diversos de regulação da vida social quanto discursos, instituições, formas arquitetônicas, enunciados científicos, proposições morais e filosóficas. (FOUCAULT, 2006, p. 244)

Ainda de acordo com Foucault, na sociedade, assim como na obra, é todo um discurso controlado: "sabe-se bem que não se tem o direito de dizer tudo, que não se pode falar tudo em qualquer circunstância, que qualquer um, enfim, não pode falar qualquer coisa". (FOUCAULT, 2009, p. 9) A sexualidade, junto com a política, seria a região onde as interdições mais atuariam: "como se o discurso, longe de ser esse elemento transparente ou neutro no qual a sexualidade se desarma e a política se pacifica, fosse um dos lugares onde elas exercem, de modo privilegiado, alguns de seus mais temíveis poderes" (FOUCAULT, 2009, p. 10). Corroborando com Foucault (2009), Butler (2010), afirma que

existem dimensões temporais e coletivas nestas ações, e o seu caráter público não é irrelevante; com efeito, a performance é efetivada com o objetivo estratégico 
de manter o gênero dentro da sua moldura binária. [...] Esta formulação afasta a concepção de gênero de um modelo de identidade substancial, levando-a para um outro que exige uma concepção de sexualidade enquanto temporalidade social construída. (BUTLER, 2010, p. 140-141)

"Na maioria das vez eu finjo que num tô lá. Ele nunca repara a diferença. Nunca me pergunta como eu me sinto, nada. Só faz o negócio dele, sai, vai dormir." (WALKER, 1982, p. 76-77). Em meio a uma sociedade regida por costumes de exploração do trabalho braçal e sexual feminino, a reprodução desses costumes passa a ser fato inevitável, no relacionamento conjugal, por exemplo, Celie é maltratada e escravizada, enquanto no relacionamento entre Celie e Doci, o afeto acalentava os dias de sofrimento, configurando essa relação em um jogo que Celie utiliza para encontrar forças para combater: crueldade com amor e dor com alegria.

Doci Avery senta u pouquinho na cama hoje. Eu lavo e penteio o cabelo dela. Ela tem o cabelo mais pixaim curto e enroscado queu já vi, e eu amo cada fio dele. $\mathrm{O}$ cabelo que ficou no meu pente, eu guardei. Quem sabe um dia eu faço uma rede, uma malha pra botar no meu próprio cabelo. (WALKER, 1982, p. 56)

Ao se tratar para se tratar das configurações do (homo)erotismo feminino em $A$ cor púrpura (1982), a linguagem é direta e sem excessos de recursos sintáticos e estéticos formais.

O que cê tá olhando?, ela pergunta. Cheia de raiva. Ela tá fraca que nem uma gatinha. Mas a boca tá cheia de garra. Você nunca viu uma mulher pelada antes? Não senhora, eu digo. Eu nunca vi. Só a Sofia, e ela é tão gorda, corada e louca que parece minha irmã. Ela diz, Bom, olha bem. Mesmo se agora eu tô que nem um saco de osso. E ela inda tem a ideia de botar uma mão no quadril pelado e piscar um olho pra mim. Depois ela chupa os dentes e fica olhando pro teto enquanto eu dou banho nela. Eu lavei o corpo dela, parece queu tava rezando. Minhas mão tremia e minha respiração ficou presa. (WALKER, 1982, p. 53)

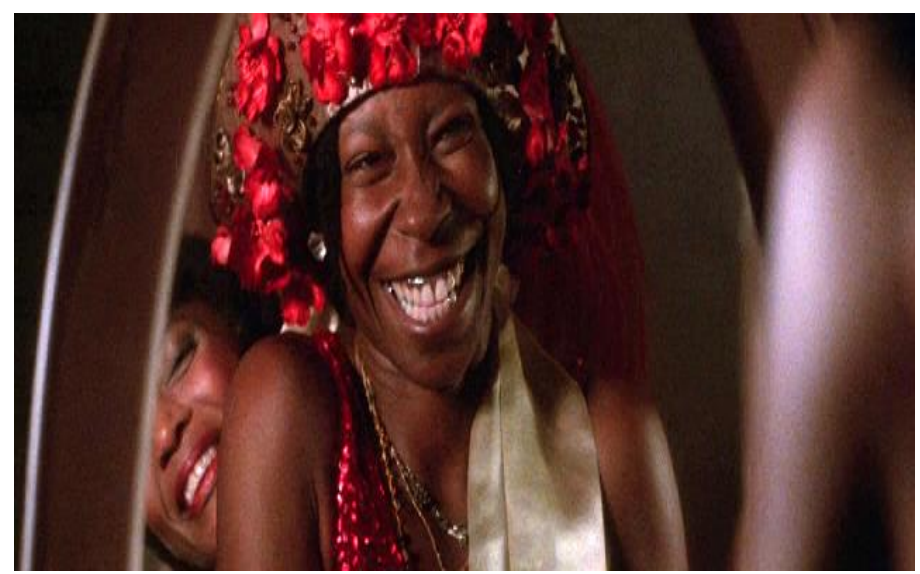

Figura 3: The color purple (1985) $116 \mathrm{~min} 34 \mathrm{~s}$

"A Doci olha pra mim e a gente ri. Aí a gente começa a dar e dar risada. Então a tampinha começa a rir. A gente quase morre de rir.” (WALKER, 1982, p. 181). A aproximação da artista faz com que Celie passe a se compreender enquanto mulher, que Revista Livre de Cinema

p. $67-78$ v.2, n. 3, set/dez, 2015 
sente seu corpo. O ápice seria a certeza de que, mesmo em meio a tantos percalços vividos, seria possível sorrir. O sorriso, antes tão distante e fugidio, se tornara fácil e espontâneo ao lado de Doci Avery.

Por outro lado, na adequação fílmica, evitam-se roteiros longos, assim como, grandes turnos de fala, verifica-se na figura 3: o cenário há baixa luz, as mãos de Celie em direção ao quadril, os ornamentos coloridos e vibrantes, e, finalmente, o fato de Celie se ver refletida no espelho, fazem com que a personagem aceite sua condição de inclinada (homo)afetivamente, mas desta vez, na perspectiva, do uso de estéticas artísticas como elemento fomentador da aceitação do corpo e da feminilidade.

Portanto, a partir das expressões (homo)afetivas enfatizamos como é explorado o tema da homossexualidade na obra $A$ cor púrpura, e como foi pensada e idealizada tal temática no âmbito cinematográfico. Busca-se, apontar características que Walker (1982) sutilmente levanta, ao evidenciar em trechos em que a homossexualidade se apresenta no sentido da afetividade, ou muitas vezes, até no sentido imaturo no contexto das relações socioculturais.

\section{Considerações finais}

A adaptação de obras literárias para o cinema é uma prática comum, o universo da literatura inspira das maneiras mais diversas as narrativas fílmicas. É evidente na literatura a valorização dos fatos, através de recursos relatais que tem grande compatibilidade com a linguagem cinematográfica, pois esta dispõe de recursos imagéticos e sonoros que facilitam a reprodução de eventos. Como explica Lúcia Santaella (2002), sobre a teoria semiótica,

[...] a semiose, ou cadeia de significado, na teoria dos signos de Charles Peirce, é constituída pela relação triádica e dinâmica entre o signo, o objeto e o interpretante, sendo que o signo é um conteúdo apreendido pelos sentidos, pela imaginação, pela memória, pelo pensamento e liga o objeto (aquilo que ele, signo, representa ou substitui) a um interpretante (efeito que o signo produz no intérprete, ou seja, a potencialidade do signo em sugerir, significar, mas que já está inscrita no próprio signo) (SANTAELLA, 2002, p. 7-8)

Neste texto, buscamos como enfoque, a verificação das traduções da sexualidade, que consideramos uma categoria de suma relevância e de caráter fundamental na constituição do enredo analisado. "A tradução coloca questões que só podem ser reveladas no nível da arte, pois esta é o produto da gangorra de interpretantes dada a impossibilidade de delimitar o interpretante final". (PLAZA, 2010, p. 210). Mesmo 
nos utilizando do recurso comparativo, a nossa intenção não foi subjugar a produção fílmica ao romance, mas procurar construir o universo particular de significações que circundam o erotismo, respeitando e valorizando cada uma delas.

Com efeito, é importante ressaltar as contribuições da tradução intersemiótica para o estudo em questão, retomando conceitos de sexualidade, (homo)afetividade, trabalhados entre obras, atualizando tais conceitos ao contexto da pós-modernidade.

Celie ganha sua liberdade, a partir do momento em que se aceita enquanto ser desejante e desejada. Para tanto, nas duas composições - Cinema e Literatura- a presença da artista, Doci Avery, se torna elemento divisor de águas dessa relação de aceitação, liberdade e poder. O poder, como puro limite traçado à liberdade, pelo menos em nossa sociedade, é a forma geral de sua aceitabilidade. (FOUCAULT, 2006, p. 94).

Portanto, procedemos com a apresentação das expressões de sexualidade na obra original, A cor Púrpura (1982), de Alice Walker, identificando de que forma se dá o processo de construção de sentidos acerca da transposição da literatura, para o exame dos produtos fílmicos derivados do romance, com o intuito de reconhecer as traduções da sexualidade e seus procedimentos em cada uma delas. Assim, tal reflexão amplia e renova a discussão estética em torno da obra, resgatando-a, como devir e, estabelecendo, assim, um diálogo fecundo com o romance, onde cada um deles colabora com o universo de interpretantes de textos em que tanto livro quanto filme contam histórias que representam as inquietações do ser humano diante da vida.

\section{Referências}

ALLEGRO, Alzira L. V. Das relações entre literatura comparada e tradução literária: algumas considerações. Revista Eletrônica: Mar/ 2004.

BAZIN, André. O cinema - ensaios. São Paulo: Editora Brasiliense, 1991.

BOURDIEU, Pierre. A dominação masculina. 3. ed. Tradução de Maria Helena Kühner. Rio de Janeiro: Bertrand Brasil, 2008.

Pierre. PASSERON, Jacques. C. A reprodução: Elementos para uma teoria do sistema de ensino. Trad. de Reynaldo Bairão. Rio de Janeiro: Francisco Alves, 1982.

BUTLER, Judith. Problemas de gênero: feminismo e subversão da identidade. Rio de Janeiro: Civilização Brasileira, 2010.

ESPÍNDOLA, Bernardo Rodrigues. Dissertação: A representação dos Evangelhos no filme A paixão de Cristo. Belo Horizonte, 2008.

Revista Livre de Cinema

p. $67-78$

v.2, n. 3, set/dez, 2015 
FOUCAULT, Michel. A ordem do discurso. São Paulo: Edições Loyola, 2009. . História da Sexualidade 1: A vontade de saber. Trad. Maria Thereza da Costa Albuquerque. - $1^{\underline{a}}$ ed. - São Paulo: Paz e Terra, 2006.

FREUD, Sigmund. O estranho. vol. XVII, Imago Ed. RJ, 1976.

HALL, Stuart. A Identidade Cultural na Pós-Modernidade. Porto Alegre, DP\&A Editora, 2006.

JAKOBSON, Roman. Linguística e comunicação. São Paulo: Cultrix, 1969.

LAJOLO, Marisa. Romance Epistolar: o voyeurismo e a sedução dos leitores. Fórum de Ciência e Cultura da UFRJ. Encontros de Escritores; Rio de Janeiro: UFRJ, ano 2, v.2. p. 61-75, 1999.

MARX, Karl. O capital. São Paulo: Abril Cultural, 1984.

PLAZA, Júlio. Tradução Intersemiótica. São Paulo: Perspectiva, 2003.

WALKER, Alice. A cor púrpura. Tradução: Peg Bodelson, Betúlia Machado e Maria José Silveira. São Paulo: Editora Marco Zero, 1982.

SANTAELLA, Lucia. Semiótica aplicada. São Paulo: Pioneira Thomson Learning, 2002.

THE COLOR PURPLE. Direção: Steven Spielberg. Produção: Steven Spielberg, Kathleen Kennedy, Frank Marshall e Quincy Hones. Roteiro: Menno Meyes, a partir do romance The color purple, de Alice Walker. Intérpretes: Danny Glover, Whoopi Goldberg, Oprah Winfrey e outros. Conspiração Filmes; Warner Bros, 2003. 1 filme DVD (154 min.) 